\title{
Trabalho, cuidado e sociabilidade: contribuições marxianas para 0 debate contemporâneo ${ }^{1}$
}

\section{Work, care and sociability: Marxian contributions to the contemporary debate}

\author{
Rachel Gouveia Passos \\ Assistente social, doutoranda do Programa de Estudos Pós-Graduados em Serviço Social \\ da Pontifícia Universidade Católica de São Paulo, São Paulo (SP), Brasil.
}

rachel.gouveia@gmail.com

\begin{abstract}
Resumo: O presente artigo apresenta elementos que localizam o cuidado enquanto resultado da coexistência ontológica entre trabalho e relações sociais. Além disso, discute acerca das condições em que o trabalho do cuidado vem sendo convocado pelas transformações ocorridas no padrão de acumulação capitalista, provocando a sua internacionalização. Por fim, problematiza as configurações da divisão social e sexual do trabalho, a mercantilização e a profissionalização dessa atividade, especificamente na política de saúde mental brasileira.
\end{abstract}

Palavras-chave: Trabalho. Cuidado. Sociabilidade. Divisão social e sexual do trabalho. Mulheres.

\begin{abstract}
This article presents elements that locate care as a result of ontological existence between work and social relationships. Further, it discusses about the conditions under which the work of care has been summoned by the transformations that have occurred in the pattern of capitalist accumulation causing its internationalization. Finally, it discusses the settings of social and sexual division of labor, the commercialization and professionalization of this activity, specifically in the Brazilian mental health policy.
\end{abstract}

Keywords: Work. Care. Sociability. Social and sexual division of labor. Women.

\section{Introdução}

o suscitar o debate sobre o cuidado na cena contemporânea cor-
remos o risco de sermos compreendidos enquanto pós-estrutura-
listas e pós-modernos, já que essa categoria vem sendo alocada,

1. O presente artigo compõe a pesquisa de doutoramento que se encontra em desenvolvimento. 
desconexa da realidade macroestrutural e de forma reduzida é um equívoco, posto que, nas configurações atuais do provimento do cuidado individual e coletivo, perpassa uma série de determinações que estão condicionadas pela sociabilidade burguesa.

A análise que está sendo proposta ao longo do presente artigo pauta-se pelo materialismo histórico-dialético, localizando o cuidado, no cenário contemporâneo, enquanto trabalho e que possui o intuito de auxiliar na satisfação das necessidades primárias dos indivíduos que se encontram incapacitados para realizá-las em determinados períodos e/ou por toda a vida. ${ }^{2}$ Além disso, é na reprodução social que localizamos o trabalho do cuidado, compreendendo-o enquanto resultado do desenvolvimento das necessidades do ser social que são consequências do processo de sociabilidade.

Portanto, ao analisarmos o trabalho do cuidado em tempos de acumulação flexível, torna-se possível não só apresentar as transformações do mundo do trabalho, da reestruturação produtiva e os impactos neoliberais, mas também localizar as opressões que são reproduzidas no cotidiano, nesse caso, especificamente, em relação às mulheres que efetuam o trabalho do cuidado, ou seja, o trabalho do care. ${ }^{3}$

Então, caminharemos em três direções: a primeira, no que diz respeito a localizar o cuidado enquanto resultado do desenvolvimento da sociabilidade humana; a segunda, como ele foi apropriado pelo mundo do trabalho no cenário contemporâneo; e a terceira é identificar o nó ontológico ${ }^{4}$ entre classe, gênero e raça/etnia existente no trabalho do cuidado executado pelas trabalhadoras do care na política de saúde mental, especificamente nos serviços residenciais terapêuticos.

2. Aqui, podemos esclarecer que os sujeitos que demandam cuidado não só por determinado período (enquanto fase natural), mas em alguns casos ao longo de toda a vida são: pessoas com deficiência, pessoas com sofrimento psíquico grave e institucionalizadas por longo período, acamados, doentes crônicos e degenerativos etc.

3. A categoria care é utilizada a partir do momento que se localiza o trabalho do cuidado na perspectiva feminista, problematizando-o no contexto contemporâneo como mercadoria. Além disso, o identificamos enquanto atividade majoritariamente feminina, vinculada a determinada "essência feminina", sustentada pela divisão sexual do trabalho e afirmado pela precarização.

4. Conceito utilizado e problematizado por Cláudia Mazzei Nogueira (2013, p. 67). 


\section{Trabalho e sociabilidade}

Para localizarmos o objeto de análise aqui proposto é preciso retomar as categorias primordiais e seus fundamentos teóricos. É a partir de Marx e de Lukács que se compreende o trabalho enquanto categoria fundante do ser social. Entretanto, é na cena contemporânea que se constitui configurações que delineiam o cuidado enquanto trabalho e mercadoria. Nessa direção, nos interessa problematizar os traços predominantes das configurações atuais do trabalho do cuidado no capitalismo contemporâneo, compreendendo-o numa relação de continuidades e descontinuidades, de traços antigos e novos e estabelecidos a partir de relações desiguais.

De acordo com Lukács (2013), o trabalho é a relação direta de interação do ser social ${ }^{5}$ com a natureza. É esse pressuposto ontológico primário que se refere às condições vitais para a existência e a sobrevivência do gênero humano, no qual, por meio do trabalho, ocorre a transformação da natureza, a transformação do indivíduo com ele mesmo e a transformação das relações sociais. Acerca das relações sociais, Lukács apresenta o pressuposto ontológico secundário (como a arte, a literatura, a filosofia, a religião, a práxis política etc.) que se supõe a partir da práxis interativa e intersubjetiva e se constituem como complexos que se colocam a partir do trabalho em sua primeira forma.

Ao longo desse processo de transformação da natureza, da transformação do ser social e das relações foi que se constituíram novas necessidades para a sua existência. Nesse movimento de mudanças, o ser social teve a possibilidade de optar por novos processos, expressos tanto na sua força de trabalho quanto no seu objeto e em seus instrumentos. Por ser um ser capaz de proceder de forma racional é que ele age teleologicamente, pois à medida

5. Utilizaremos de forma hegemônica a terminologia ser social para nos referirmos aos indivíduos. Tem-se a preocupação de não afirmar um olhar que reforce o masculino, o elevando (ainda mais) enquanto universal. É importante assinalar que ao utilizar a palavra homem no que se refere ao humano genérico, apresenta-se uma concepção generalista, e não preocupada com a divisão social e sexual do trabalho e das relações. Destaca-se que ao considerar que as relações sociais são determinadas historicamente, é preciso problematizar de que forma elas se colocam diferenciadas para homens e para mulheres. 
que atua sobre a natureza, produzindo a transformação da mesma, ocorre em sua consciência uma projeção ideal do resultado que se quer alcançar. Essa forma de transformar a natureza é iminentemente exclusiva do ser social, o que o diferencia dos animais.

É importante assinalar que o trabalho enquanto base dinâmico-estruturante do ser social só ocorreu após determinado grau de desenvolvimento do processo de reprodução orgânica. Ou seja, é pela consciência que o trabalho se consiste, saindo de uma simples competição biológica dos seres vivos para sua sobrevivência no meio ambiente. Portanto, é na prévia ideação (teleologia) de uma ação que se quer realizar que se atribui à consciência um papel decisivo: a materialização dessa idealização (Lukács, 1978).

Nesse movimento de busca pelas satisfações humanas materiais se constituíram novos processos, objetos e instrumentos, e claro, novas e diversas necessidades e capacidades. Ao transformar a natureza na busca da satisfação de suas necessidades, o ser social se transforma e se modifica, produzindo as relações sociais, constituindo sua humanidade e construindo a história.

No livro A ideologia alemã, os autores assinalam que o primeiro pressuposto de toda a história humana é a própria existência dos indivíduos. É na organização corporal desses sujeitos e por meio dela que se estabelece a relação com a natureza. Ou seja, "toda historiografia deve partir desses fundamentos naturais e de sua modificação pela ação dos homens no decorrer da história" (Marx e Engels, 2007, p. 87).

Entretanto, para o ser social "fazer história", antes de tudo é preciso alimentar-se, beber, vestir-se, morar e outras coisas mais. O primeiro ato histórico é a produção dos meios que possibilitem a satisfação das necessidades materiais. "O modo pelo qual os homens produzem seus meios de vida depende antes de tudo da própria constituição dos meios de vida já encontrados e que eles têm de reproduzir" (idem). É claro que esse modo de produção não pode ser reduzido apenas ao aspecto da reprodução física, mas antes de tudo é "uma forma determinada de sua atividade, uma forma determinada de exteriorizar a vida, um determinado modo de vida desses indivíduos" (Marx e Engels, 2007, p. 87). 
Essas determinações também implicam sobre as relações sociais. Há um entrelaçamento das relações sociais com o comportamento produzido pelas condições materiais que resultam em formas de ser determinadas, que condicionam os indivíduos, seus comportamentos, representações e ideias, a partir do desenvolvimento das forças produtivas e por seu intercâmbio. Portanto, a consciência é moldada e determinada de acordo com a realidade vivenciada pelo ser social (Ibidem).

Em relação ao segundo ato histórico, o mesmo está relacionado à ação de satisfazer a primeira necessidade e o instrumento de satisfação adquirido anteriormente dirigindo a criação de novas necessidades. Logo, a produção de novas necessidades integra a composição do primeiro ato histórico (Marx e Engels, 2007, p. 33).

O terceiro ato está relacionado ao desenvolvimento histórico dos indivíduos, em que na própria renovação da vida cotidiana inicia-se o processo de criação de outros seres, de procriar (a relação entre homem e mulher, pais e filhos) e de fundar a família. É através da família que se constitui, inicialmente, "a única relação social, torna-se mais tarde, quando as necessidades aumentadas criam novas relações sociais e o crescimento da população gera novas necessidades, uma relação secundária” (Ibidem).

Nesse processo, há uma coexistência em relação a esses três momentos: "a produção da vida, tanto da própria, no trabalho, quanto da alheia, na procriação, aparece desde já como uma relação dupla — de um lado, como relação natural, de outro como relação social" (Idem, p. 34). Essa relação social, para os autores, é expressa no sentido de que por ela se entende a cooperação de vários indivíduos. Portanto, é através desse processo de cooperação que podemos localizar elementos que identificam o cuidado enquanto resultado da coexistência do trabalho e das relações sociais.

Pensar o cuidado enquanto resultado da coexistência de trabalho e relações sociais possibilita-nos apontar as seguintes questões: 1) Enquanto procriação, existe a necessidade de se pensar a sobrevivência dos indivíduos que não podem executar o trabalho para satisfazer as suas necessidades ontológicas primárias; logo, é preciso que um outro trabalhe para satisfazê-los; 
2) Enquanto relação social será determinado como, por quem, onde e de que forma o cuidado deve ser executado. Logo, resulta de determinadas necessidades sociais estipuladas a partir do desenvolvimento da sociabilidade e das forças produtivas.

Cabe assinalar que a constituição da família ${ }^{6}$ foi fundamental para a organização dessa atividade, estabelecendo-a enquanto atribuição social a um de seus membros e às suas formas de execução. ${ }^{7}$ É nesse espaço que se torna possível reproduzir modos de vida social.

Entretanto, foi no contexto da sociedade capitalista que a família nuclear se estabeleceu e perpetuou-se, sendo-lhe atribuída um papel extremamente importante na reprodução dos valores criados. ${ }^{8}$ Essa forma de organização societária tem como fundamento a existência das desigualdades de classes distintas e antagônicas, ocasionando uma não satisfação das necessidades de todos os indivíduos. Além disso, sustenta-se pelo caráter individualista da apropriação privada dos meios de produção e da mercantilização dos produtos e da força de trabalho.

Marx em $O$ capital (2013), aponta que o processo de transformação da natureza, que advém de determinada necessidade ontológica e que resulta, enquanto produto do trabalho, no capitalismo, é apropriado e torna-se mercadoria, ficando encoberto o trabalho humano e assumindo forma de relações sociais os produtos do trabalho. É nesse processo que se tem assentado a

6. Segundo Almeida (2014, p. 189), “a família dispõe de um lugar 'natural' de proteção dos sujeitos. De acordo com os estudos antropológicos, além de ser um grupo social, a família constitui-se em um 'valor'. De modo que a intensificação do cuidado pela família reatualiza velhos conceitos, como características e aptidões naturais de gênero ou ainda solidariedade intergeracional, entre outros. Elementos que configuram o 'sentimento de família', as definições sobre o que uma família é para um sujeito, marcadamente um grupo com o qual se pode contar, onde se oferece ajuda etc.".

7. “Com a divisão do trabalho, [...] que, por sua vez, se baseia na divisão natural do trabalho na família e na separação da sociedade em diversas famílias opostas umas às outras, estão dadas ao mesmo tempo a distribuição e, mais precisamente, a distribuição desigual, tanto quantitativamente quanto qualitativamente, do trabalho e de seus produtos; portanto, está dada a propriedade, que já tem seu embrião, sua primeira forma, na família, onde a mulher e os filhos são escravos do homem” (Marx e Engels, 2007, p. 36).

8. De acordo com Morgado (2004, p. 2), “considera-se a família uma instituição social, que se modifica de acordo com a transformação histórica de cada sociedade, estando atravessada pelas relações de poder e dominação tal como as demais instituições sociais". 
alienação, a desumanização e a desigualdade social, que resultam no enriquecimento e na satisfação de poucos em detrimento das reais necessidades sociais da grande maioria. Portanto, reproduz-se um modelo de sociabilidade - principalmente através da família - que afirma e sustenta essa lógica organizacional. Nesse caminho, é imprescindível localizarmos temporalmente a introjeção do cuidado enquanto mercadoria no cenário internacional.

\section{A mercantilização do cuidado}

A partir do início da década de 1970, o capital se subjugou em resposta à sua própria crise a um processo de reorganização produtiva em escala global, tendo repercutido não só no sistema econômico, mas também no plano ideológico e político de dominação. Suas expressões mais radicais colocam-se expressas no neoliberalismo, na reforma do Estado, na desregulamentação dos direitos trabalhistas, na desmontagem do setor produtivo estatal e no processo de reestruturação da produção e do trabalho (Antunes, 2013).

Essa proliferada ofensiva do capital e do Estado contra a classe-que-vive do trabalho ${ }^{9}$ teve enquanto propósito a destruição dos direitos conquistados por meio da precarização e da flexibilização, ${ }^{10}$ expressos através de distintas formas de contratação: empresa enxuta, empreendedorismo, cooperativismo, trabalho voluntário, subcontratação, trabalho temporário etc. (Antunes, 2009).

9. "Desde logo é preciso indicar que a classe trabalhadora compreende a totalidade dos assalariados, homens e mulheres que vivem da venda da força de trabalho, a classe-que-vive-do-trabalho e que são despossuídos dos meios de produção" (Antunes, 2009, p. 51).

10. "Dentre as distintas formas de flexibilização - em verdade precarização - podemos destacar a salarial, de horário, funcional ou organizativa, dentre outros exemplos. A flexibilização pode ser entendida como 'liberdade da empresa' para desempregar trabalhadores; sem penalidades, quando a produção e as vendas diminuem; a liberdade, sempre para a empresa, para reduzir o horário de trabalho ou de recorrer a mais horas de trabalho; possibilidade de pagar salários reais mais baixos do que a paridade de trabalho exige; possibilidade de subdividir a jornada de trabalho em dia e semana segundo as conveniências das empresas, mudando os horários e as características do trabalho (por turno, por escala, em tempo parcial, horário flexível etc.), dentre tantas as formas de precarização da força de trabalho" (Antunes, 2009, p. 50-51). 
Destaca-se que apesar do aumento intensivo dos níveis de desemprego estrutural ocorreu, ao mesmo tempo, o avanço tecnológico que poderia contribuir com a redução da jornada de trabalho. Todavia, "pode-se presenciar, em vários países, como a Inglaterra, uma política de prolongamento da jornada de trabalho" (Antunes, 2013, p. 15). Tais características demarcam a era da acumulação flexível, sendo essas algumas das respostas dadas à crise estrutural do capital que perdura até os dias atuais.

Nessa nova morfologia do trabalho ${ }^{11}$ ocorreu o aprofundamento da divisão sexual do trabalho, proporcionando um aumento significativo da participação das mulheres no mercado e resultando na demissão em massa de homens. Isso significa que, por um lado, as mulheres encontram cada vez mais empregos e os homens, cada vez menos. Entretanto, de que forma se deu essa inserção feminina no trabalho?

De acordo com Nogueira (2013), foi nesse contexto que se instaurou "a feminização do mundo do trabalho", ${ }^{12}$ no qual as mulheres ocuparam os empregos precários e de maior flexibilização. Essa intensificação da presença feminina no mundo trabalhista não se deu por acaso, já que ela possibilitou a incorporação e o aumento da exploração das mulheres em ocupações de tempo parcial, em trabalhos domésticos subordinados ao capital, além da participação em massa nos setores de serviços.

Em uma perspectiva que analisa esse fenômeno no cenário internacional é que Hirata (2010) problematiza os paradoxos do emprego feminino na era da acumulação flexível. Para essa pesquisadora existe uma indissociabilidade em relação à divisão sexual do saber e do poder entre homens e mulheres, expressa tanto na sociedade quanto nas relações familiares. $\mathrm{Ou}$ seja, as "responsabilidades tradicionais das mulheres pela educação das

11. "Compreender a classe trabalhadora hoje, de modo ampliado, implica entender este conjunto de seres sociais que vivem da venda da sua força de trabalho, que são assalariados e são desprovidos dos meios de produção. Nessa (nova) morfologia da classe trabalhadora, sua conformação é ainda mais fragmentada, mais heterogênea e mais complexificada do que aquela que predominou nos anos de apogeu do taylorismo e do fordismo" (Antunes, 2003, p. 218).

12. Para maior aprofundamento, ver Cláudia Mazzei Nogueira (2004). 
crianças estruturam mercados de trabalho e que são desvantajosos para as mulheres, resultando em um poder desigual no mercado econômico" (Hirata, 2010, p. 1), o que não deixa de reforçar o poder desigual existente no seio familiar.

Em seu artigo "Novas configurações da divisão sexual do trabalho", Helena Hirata (2010) destaca quatro aspectos das configurações atuais da divisão social e sexual do trabalho em um contexto internacional: 1) Divisão sexual do trabalho profissional e doméstico; 2) Precarização social e do trabalho; 3) A expansão do care e das migrações internacionais femininas e 4) A globalização e a divisão sexual do trabalho. Trataremos de forma breve cada um desses fenômenos.

No que diz respeito à divisão sexual do trabalho profissional e doméstico, pode-se destacar certa bipolarização que é resultado dos processos educacionais. As mulheres são mais instruídas do que os homens em todos os níveis de escolaridade em diversos países. Entretanto, de um lado encontram-se mulheres formadas com nível superior e do outro lado mulheres que estão em setores tradicionalmente femininos (empregadas domésticas, auxiliares de enfermagem, professoras de ensino básico, prestadoras de serviços etc.). Esse fenômeno ocasiona um agravamento no que diz respeito às desigualdades sociais, tanto entre mulheres e homens, quanto entre as próprias mulheres (Hirata, 2010).

No caso das profissionais de nível superior e que possuem salários melhores, ocorre uma delegação das atividades domésticas e de cuidados para as mulheres que compõem o outro polo da bipolarização. Apesar de as mulheres conquistarem a ocupação do mercado de trabalho - ainda que de forma contraditória e precária —, são elas que predominam na efetivação do trabalho doméstico. No caso brasileiro, é importante assinalar que não existe apenas a desigualdade de classes entre as próprias mulheres; há também a desigualdade racial/étnica.

Para o exercício de atividades fora do espaço doméstico, é trivial que as mulheres precisem delegar tarefas da administração de suas casas a outras 
mulheres. No caso brasileiro, essas são práticas de longa duração histórica que reafirmam a maternidade transferida, forma de as mulheres atribuírem-se mútua responsabilidade, legitimada nas lutas feministas. Essa transferência atualiza desigualdades seculares nos acessos das mulheres a direitos sociais, próprias das relações de poder e subordinação que presidem a montagem dos sistemas protecionistas. (Costa, 2002, p. 303-304)

Sobre a hierarquização do trabalho entre ambos os sexos, é importante frisar que as mulheres, apesar de possuírem maior escolarização, ganham salários mais baixos. Além disso, são as mulheres negras que se localizam na base da pirâmide com as piores remunerações e escolarização, afirmando, portanto, a desigualdade de classe, gênero e raça/etnia (Sorj e Fontes, 2012).

Em relação à precarização social e do trabalho destacam-se a vulnerabilidade, a instabilidade, a má remuneração e o pouco valor social. Existe uma intensificação do trabalho precarizado e flexibilizado aliado à precarização familiar, principalmente no que diz respeito aos novos arranjos familiares. As famílias monoparentais são as mais atingidas, já que são chefiadas, em sua maioria, por mulheres que precisam trabalhar e cuidar de seus filhos. Os empregos que apresentam maior flexibilidade proporcionam um melhor ajuste em relação às múltiplas jornadas de trabalho dessas mulheres.

O modelo de trabalho vulnerável e flexível assumiu, nos países do Norte, a figura do trabalho em tempo parcial e, nos países do Sul, a do trabalho informal, desprovido de status sem nenhuma proteção social. As trabalhadoras pobres (working poors) e as "famílias monoparentais" (termo neutro que oculta o fato de que se trata majoritariamente de mães solteiras) estão aumentando em muitos países do Norte e do Sul. (Hirata, 2009, p. 31)

No tocante à expansão das atividades relacionadas ao care (cuidados para crianças, deficientes, idosos, pessoas com transtorno mental e demais sujeitos incapacitados), Hirata (2010) destaca que se concebeu, nas últimas décadas, um fluxo migratório internacional. Carrasco (2001, apud Hirata, 2010 , p. 4) denomina essa realidade de "internacionalização do trabalho reprodutivo". 
Esse fenômeno proporciona a saída de milhões de mulheres dos países do hemisfério sul para o norte em busca de trabalho. Como é uma atividade que ainda é assumida, majoritariamente, por mulheres, encontra-se vinculada a certa "naturalização e essencialização" do care como inerente ao modo de ser feminino. Para Hirata (2010, p. 5), tem-se como consequência dessa vinculação "a desvalorização da profissão do care". ${ }^{13}$

No campo das ciências sociais, especialmente na sociologia do trabalho, os estudos direcionados ao trabalho do care vêm tendo um crescimento demasiadamente significativo. A problematização do reconhecimento das ditas qualidades femininas (a competência relacional, o provimento do cuidado) enquanto qualidades profissionais se faz necessária urgentemente. $\mathrm{Ou}$ seja, as atividades realizadas pelas mulheres que estão atreladas a essas qualidades devem ser reconhecidas enquanto trabalho no cenário contemporâneo. É importante frisar que tem sido através do setor de serviços que esse tipo de trabalho vem sendo convocado e mercantilizado. Esse setor

permite evidenciar que frequentemente a força de trabalho feminina tem como característica as atribuições mais precárias, sendo responsáveis, em boa parte dos casos, pelas tarefas monótonas, repetitivas e estressantes do trabalho part-time, entre outras. Isso só é possível porque as mulheres se encontram diretamente articuladas às relações de poder presentes na histórica afirmação que o trabalho feminino tem menos valor que o masculino em virtude prioritariamente de suas especificidades "naturais" de mãe e esposa. (Nogueira, 2013, p. 76-77)

Por fim, Hirata (2010, p. 5) assinala que os efeitos da globalização são diferenciados em relação a homens e mulheres, e por isso os fenômenos devem ser analisados com recorte de gênero: "As dinâmicas de classe, de 'raça' e os movimentos migratórios não podem ser compreendidos sem a

13. "O 'care', como atividade profissional, tem um caráter explosivo, pois questiona a gratuidade do trabalho doméstico, a 'servidão voluntária' efetuada no espaço privado. $\mathrm{O}$ 'care' como profissão implica no reconhecimento e na valorização do trabalho doméstico e familiar como trabalho” (Hirata, 2010, p. 5). 
perspectiva de gênero. O gênero é um organizador-chave da globalização neoliberal".

Já para Nobre (2004), uma primeira constatação do movimento de mulheres, em relação ao contexto neoliberal, deu-se a partir do aumento das múltiplas jornadas decorrentes dos ajustes estruturais. A participação feminina frente a essas mudanças ocorreu pela intensificação dos cuidados voltados para as crianças, idosos, doentes, bem como da gestão de programas sociais. Portanto, foram geradas algumas consequências, contraditórias e articuladas, diante desse novo cenário: a "crise no padrão de reprodução, a mercantilização da reprodução e o reforço ao papel das mulheres como cuidadoras" (p. 64).

Tais características apresentam o crescimento da atividade doméstica e de cuidados, sinalizando os sacrifícios que as mulheres assumem numa esfera internacional. Esses sacrifícios nem sempre são retribuídos no aspecto financeiro, pois 'uma grande parte desse setor de 'care', constituído pela migração internacional, trabalha na informalidade e em situação precária, um dos traços das novas configurações da divisão sexual do trabalho" (Hirata, 2010, p. 5).

Em vista disso, é de suma importância avançar na identificação das múltiplas modalidades do trabalho de care, sendo primordial a observação das formas de "como o mercado (vale dizer, a mercantilização do care e a profissionalização daqueles/as que são os prestadores desse serviço) e as políticas públicas influenciam nesse processo" (Guimarães, Hirata e Sugita, 2011, p. 155). Nesse caminho, pretende-se localizar elementos que problematizem a realidade das trabalhadoras do care na política de saúde mental brasileira, dando destaque aos serviços residenciais terapêuticos.

\section{Trabalhadoras do care na saúde mental}

Desde a implantação da política de saúde mental, pautada nos princípios e diretrizes da Reforma Psiquiátrica Brasileira (RPB), têm sido requisitadas mudanças que possibilitem a transformação da atenção centrada no hospital 
psiquiátrico para o modo de atenção psicossocial. Essas transformações na saúde mental vieram atreladas a Reforma Sanitária e ao processo de redemocratização que ocorriam no país nos anos 1980. A nova compreensão do processo saúde-doença ${ }^{14}$ encontra-se acompanhada pela conquista dos direitos sociais expressos não só pela Constituição de 1988, mas também pelas Leis ns. 8.080 e 8.192, ambas de 1990, que dispõem acerca do Sistema Único de Saúde.

Logo, o cuidado prestado na atenção psicossocial apresentou novas demandas de atividades e atribuições ao campo, possibilitando a inserção de trabalhadores que não precisam de uma formação específica para operacionalizar o cuidado em saúde mental. Essas novas atividades vinculam-se à concepção de desinstitucionalização influenciada pela experiência italiana de reforma psiquiátrica. Nesse caminho, objetivou-se a desconstrução da lógica manicomial não apenas na destituição do manicômio enquanto modelo de tratamento, mas na mudança da concepção da experiência da loucura e seus impactos nas relações sociais.

Dessa forma, o modelo de cuidado na atenção psicossocial prevê o envolvimento amplo (de familiares, comunidade, sociedade e instituições), além da responsabilização dos profissionais, facilitando a criação de uma rede de auxílio psicológico, social e cultural e alargando o campo de atuação no território: a comunidade e as (inter-) relações socioafetivas. (Silva, Vaz e Campos, 2014, p. 240)

No caso brasileiro, criaram-se os serviços residenciais terapêuticos (SRT) ${ }^{15}$ para que pudessem viabilizar moradias a pessoas que possuem internações prolongadas, ou seja, têm no hospital psiquiátrico a sua moradia. São nesses dispositivos considerados híbridos — um misto de

14. A concepção de saúde-doença aqui compreendida não se restringe à ideia de que possuir saúde seja a ausência de doença, e sim de que a saúde é muito mais ampla do que isso e de que está vinculada ao acesso aos direitos sociais, como: habitação, alimentação, assistência, educação, lazer, cultura etc.

15. Para maiores informações acerca dessa experiência em nível nacional e internacional, ver Rachel Gouveia Passos e Sílvia Portugal (2015). 
residência e tecnologia em saúde — que localizamos o trabalho de care de forma mais clara.

Como na atenção psicossocial "todos os trabalhadores são considerados agentes do cuidado" e fazem parte de um cotidiano que o produz, torna-se necessário compreender de que forma ele se caracteriza nos SRTs e como é executado pelas cuidadoras (Silva, Vaz e Campos, 2014, p. 240).

O cuidador é um profissional importante no projeto. Ele passa a operar em uma residência e isso causa impactos importantes. Os profissionais que cuidam de moradores do SRT deverão saber dosar sempre o quanto de cuidado deverá ser oferecido para auxiliar na aquisição de autonomia pelo usuário, numa negociação constante. Este novo lugar de trabalho também vai requerer dos profissionais a realização de atividades que vão muito além de sua formação inicial, tais como: auxiliar em tarefas domésticas, ajudar no pagamento de contas, na administração do próprio dinheiro etc., requerendo dos trabalhadores o desenvolvimento de novas formas de cuidar. (Ministério da Saúde, 2004, p. 12; grifos meus)

Quando tratamos os cuidadores a partir da concepção da divisão sociossexua $1{ }^{16}$ do trabalho, localizamos essa atividade enquanto uma ocupação que é executada majoritariamente por mulheres e vinculada a determinada "essência feminina". ${ }^{17}$ Ao retomarmos Hirata (2010), no que tange à bipolarização, é possível identificar nessas mulheres aquelas que se encontram no polo das atividades predominantemente femininas, mal remuneradas, precarizadas e subalternizadas. Portanto, uma primeira questão encoberta e não questionada pela Saúde Mental é sobre a "convocação" dessas mulheres para atuar enquanto pilares desse processo. ${ }^{18}$

16. Essa terminologia foi introduzida por Cláudia Mazzei Nogueira (2013) para referir-se à divisão social e sexual do trabalho.

17. Características expressas na própria concepção sobre cuidadores do Ministério da Saúde (2004). Vide citação que antecede o parágrafo.

18. Para maior aprofundamento, ver Rachel Gouveia Passos (2014). 
Diante disso, podemos assinalar dois pontos: o primeiro diz respeito à conjuntura em que a política de saúde mental veio se consolidando. A partir de 1992, a RPB se estabeleceu enquanto política, ao mesmo tempo em que tínhamos a chegada do neoliberalismo, das transformações do mundo do trabalho e da reestruturação reprodutiva. Logo depois, com os governos Fernando Henrique Cardoso e Luiz Inácio Lula da Silva, deu-se o estabelecimento dessa nova organização das forças produtivas e suas expressões mais radicais através da contrarreforma do Estado, da desregulamentação dos direitos trabalhistas, do fortalecimento dos princípios do mercado, da precarização, da flexibilização, da terceirização, da privatização dos serviços públicos etc. Mesmo diante desse cenário tão catastrófico para a classe-que-vive-do-trabalho, a RPB se consolidou, apesar de seus limites e impasses.

Em relação ao segundo ponto, podemos dizer que a RPB é uma política que, apesar dos impasses existentes nas atuais configurações, tem sido bem-sucedida em sua implantação, se comparada, por exemplo, ao caso de Portugal. ${ }^{19}$ Entretanto, não está isenta das transformações internacionais e de seus impactos em relação à divisão sociossexual do trabalho, a internacionalização do trabalho reprodutivo e no que diz respeito ao fortalecimento da exploração/opressão de classe, gênero, raça/etnia.

Ao problematizarmos acerca do trabalho de care, nessa política específica, localizamos configurações de continuidades e descontinuidades relacionadas às particularidades brasileiras. É claro que o mercado vem utilizando as atividades de caráter doméstico em novos postos de mercados de cuidado, no caso do cenário internacional pelas imigrantes, ${ }^{20}$ mas no Brasil são as mulheres negras das camadas mais pobres e sem formação que fazem esse trabalho.

19. Para maiores informações acerca dessa experiência em nível nacional e internacional, ver Rachel Gouveia Passos e Sílvia Portugal (2015).

20. Gorfinkiel (2008) denomina esse fenômeno de "cadeia global de cuidados". Na Espanha, ele é marcado pela divisão sexual e étnica do trabalho. 
No que se refere às residências terapêuticas, é importante lembrar que sua organização é em formato de casa. Apesar de constar na legislação como serviço - para fins do recebimento do seu financiamento e da contratação da equipe - , essas moradias encontram-se no seio do território e da comunidade. Portanto, as cuidadoras possuem um papel extremamente importante na construção do diálogo com a comunidade, na viabilização da autonomia e na emancipação política desses sujeitos.

Ao mesmo tempo, é viável localizar, nesse cotidiano, práticas de cuidado com caráter maternalista, ${ }^{21}$ pois em algumas situações as próprias trabalhadoras desconhecem o propósito do seu trabalho, recorrendo aos recursos "naturais" de cuidado. Um dos elementos que fortalece essa naturalização encontra-se na não exigência de uma formação e no não reconhecimento dessa atividade enquanto profissão. Isso não quer dizer que não seja possível a reprodução dessas práticas com uma formação. Entretanto, o que vem ocorrendo é certo fortalecimento do cuidado vinculado a determinada "essência feminina".

É possível notar, nos relatos e publicações de experiências em SRTs, diferenças nas atribuições do trabalho do cuidador e no modo de contratação e capacitação, o que parece ocasionar certo tipo de entrave no cotidiano dos SRTs. Por exemplo, alguns cuidadores são contratados somente como empregados domésticos, com a atribuição de manter a higiene da casa e ser responsável pela alimentação; em outros casos o cuidador terá como tarefa mediar a rotina da casa com relação a cumprimento de horários, higiene, administração da medicação etc. (Silva, Vaz e Campos, 2014, p. 243)

Além disso, é importante assinalar que na saúde mental há uma hegemonia no que diz respeito às práticas psicologizantes. Ao que parece, apesar de travarmos uma luta frente à desconstrução da hierarquização de saberes

21. Para Saffioti (1987), a sociedade investe em certa naturalização das posições sociais dos sexos. "Isto é, tenta fazer crer que a atribuição do espaço doméstico à mulher decorre de sua capacidade de ser mãe" (p. 9). Portanto, é "natural” a dedicação das mulheres às atividades domésticas e de cuidado. 
que direcionam o fazer na saúde mental, não se tem escapado das correntes da psicologia. A influência da psicanálise, da fenomenologia, da terapia cognitiva ou comportamental vem ganhando espaço nas ações antimanicomiais. É nesse campo de disputa que se localiza a justificativa para a não especialização das cuidadoras, sendo "sustentada na tentativa de garantir a quebra da medicalização, patologização e psicologização dos comportamentos dos usuários do serviço a partir de um olhar "não técnico" (Figueiredo e Frare, 2008, p. 91).

Esse olhar "não técnico" enxergado a partir da categoria trabalho e da divisão sociossexual nos possibilita afirmar que essa justificativa apenas fortalece e encobre as desigualdades de classe, gênero, raça/etnia. A luta por uma sociedade sem manicômios deve ter inclusa em seus princípios a desconstrução de todas as desigualdades e estar vinculada a um projeto societário que vise a transformação e, assim, não ser utilizada enquanto instrumento dos interesses capitalistas e burgueses para fortalecer seus princípios e modos de sociabilidade.

Por fim, salientamos que essas trabalhadoras estão sendo contratadas através de vínculos estipulados a partir de convênios (parcerias público-privado), ou seja, pela terceirização. Isso demonstra o impacto da refração do investimento público nas políticas e o aumento da privatização dos serviços de saúde. Portanto, coloca-se em xeque as próprias diretrizes da RPB frente a essa realidade, já que essas trabalhadoras são contratadas por uma instituição e recebem por outra - nesse caso o $\operatorname{Caps}^{22}$ - a direção técnica do trabalho. Além disso, esses vínculos são precários, instáveis e flexíveis para que se possa, em nome de uma sociedade sem manicômios, promover maior autonomia, cidadania e emancipação política das pessoas em sofrimento psíquico, às custas da invisibilidade e da subalternidade do trabalho do cuidado executado pelas mulheres.

22. Centro de Atenção Psicossocial. Local de tratamento dos moradores dos serviços residenciais terapêuticos. Apesar de as SRTs serem serviços independentes dos CAPs, o trabalho é realizado em conjunto, já que uma equipe cuida do morar e a outra da vida clínica desse sujeito. Entretanto, ambas não andam desarticuladas. 


\section{Algumas considerações}

Neste artigo buscou-se suscitar elementos acerca do cuidado enquanto temática de extrema importância, não só para o campo da Saúde Mental, mas também no que diz respeito ao Serviço Social. Tratá-lo a partir do materialismo histórico-dialético permite localizar esse assunto sem reduzi-lo a fenômenos meramente subjetivos e existenciais, inscrevendo-o enquanto necessidade social do humano genérico e localizando-o na divisão social e sexual do trabalho. Logo, foi possível assinalar que o cuidado se torna elemento fundamental não só para a procriação e a perpetuação da espécie, mas também enquanto pilar no processo de cooperação entre os sujeitos.

Enquanto tema que se localiza invisível no campo da Saúde Mental e no Serviço Social, evidenciou-se que no cenário contemporâneo o cuidado encontra-se mercantilizado em uma esfera internacional, expressão esta da divisão sociossexual do trabalho e de suas novas configurações. O recorte de gênero nos viabiliza assinalar as opressões que estão "naturalizadas" no que diz respeito à viabilização do cuidado não só como mercadoria, mas como atividade inerente à "essência feminina". Isso nos mostra que para todas as esferas (produção e reprodução) o trabalho do cuidado é utilizado para perpetuar o modo de vida disseminado pela sociabilidade burguesa.

Em relação à saúde mental, cabe problematizar de que forma o trabalho do care vem sendo colocado enquanto uma importante estratégia de sustentação, não só do processo de desinstitucionalização, mas também na construção de uma outra forma de se relacionar com a loucura no território e na comunidade. É fundamental que essas trabalhadoras tenham reconhecida sua profissão, obtenham uma formação crítica e não sejam subjugadas pela hierarquização dos saberes e poderes dos demais profissionais do campo da saúde mental. Tudo isso implica diretamente a viabilização do cuidado para as pessoas em sofrimento psíquico, já que o objetivo é proporcionar-lhe um novo lugar social pautado na cidadania, na autonomia e na emancipação política.

Enfim, é necessário assinalar que as práticas do cuidado em saúde mental encontram-se atravessadas pelo recorte de classe, gênero, raça/etnia, 
sexualidade etc. e que elas ainda se revelam encobertas e invisíveis. Destacá-las possibilita-nos apresentar outros e novos caminhos para desconstruirmos uma sociedade desigual e opressora. Contudo, é preciso desmistificar, no Serviço Social, que o debate sobre o trabalho do cuidado se restringe ao campo da saúde e da saúde mental, já que essa variável está vinculada às necessidades do ser social. Por isso, tratá-la no âmbito mais amplo viabiliza repensar que novas formas de cuidar serão possíveis em uma outra sociedade.

\section{Recebido em: 15/1/2016 - Aprovado em: 23/2/2016}

\section{Referências bibliográficas}

ALMEIDA, C. C. L. Saúde e cuidado: elementos para o trabalho com famílias. In: DUARTE, M. J. O. et al. Política de saúde hoje: interfaces \& desafios no trabalho de assistentes sociais. São Paulo: Papel Social, 2014.

ANTUNES, R. Perenidade (e superfluidade) do trabalho: alguns equívocos sobre a desconstrução do trabalho. In: SILVA, J. F. S.; SANT’ANA, R. S.; LOURENÇO, E. A. S. Sociabilidade burguesa e Serviço Social. Rio de Janeiro: Lumes Juris, 2013. p. 15-27, 2013. (Col. Nova de Serviço Social.)

. O trabalho, sua morfologia e a era da precarização estrutural. Theomai, Argentina, n. 19, 1. sem. 2009.

. A nova morfologia do trabalho e o desenho multifacetado das ações coletivas. In: SANTANA, M. A.; RAMALHO, J. R. Além da fábrica: trabalhadores, sindicatos e a nova questão social. São Paulo: Boitempo, 2003.

COSTA, S. G. Proteção social, maternidade transferida e lutas pela saúde reprodutiva. Estudos Feministas, Florianópolis, ano 10, p. 301-323, 2. sem. 2002.

FIGUEIREDO, A. C.; FRARE, A. P. A função da psicanálise e o trabalho do psicanalista nos serviços residenciais terapêuticos. Revista Latinoamericana de Psicopatologia Fundamental, São Paulo, v. 11, n. 1, p. 82-96, mar. 2008. 
GORFINKIEL, M. D. El mercado de trabajo de los cuidados y la creación de las cadenas globales de cuidado: ¿como concilian las cuidadoras? Cuadernos de Relaciones Laborales, Madri, v. 26, n. 2, p. 71-89, 2008.

GUIMARÃES, N. A.; HIRATA, H. S.; SUGITA, K. Cuidado e cuidadoras: o trabalho do care no Brasil, França e Japão. Sociologia \& Antropologia, Rio de Janeiro, v. 1, p. 151-180, 2011.

HIRATA, H. Novas configurações da divisão sexual do trabalho. Revista Tecnologia e Sociedade, 2. ed., Curitiba, p. 1-7, 2010.

. A precarização e a divisão internacional e sexual do trabalho. Sociologia, Porto Alegre, ano 11, n. 21, p. 24-41, jan./jun. 2009.

LUKÁCS, G. As bases ontológicas do pensamento e da atividade do homem. In: et al. Temas de ciências humanas. São Paulo: Ciências Humanas, 1978. v. 4, p. 1-18. . Para uma ontologia do ser social II. São Paulo: Boitempo, 2013.

MARX, K. O capital: crítica da economia política - Livro 1: O processo de produção do capital. São Paulo: Boitempo, 2013.

; ENGELS, F. A ideologia alemã. São Paulo: Boitempo, 2007.

MINISTÉRIO DA SAÚDE. Residências terapêuticas: o que são, para que servem. Brasília, 2004.

MORGADO, R. Família(s): Permanências e mudanças. Os lugares sociais de mulheres e homens. In: CONGRESSO LUSO-AFRO-BRASILEIRO DE CIÊNCIAS SOCIAIS, 8. A questão social no novo milênio. Coimbra, 2004.

NOBRE, M. Trabalho doméstico e emprego doméstico. In: COSTA, A. A. et al. (Orgs.). Reconfigurações das relações de gênero no trabalho. São Paulo: CUT, 2004.

NOGUEIRA, C. M. A precarização e a divisão sociossexual do trabalho. In: SILVA, J. F. S.; SANT'ANA, R. S.; LOURENÇO, E.A. S. Sociabilidade burguesa e Serviço Social. Rio de Janeiro: Lumes Juris, 2013. p. 63-81. (Col. Nova de Serviço Social.) . A feminização no mundo do trabalho. Campinas: Autores Associados, 2004.

PASSOS, R. G. Novas configurações do "care" no Brasil: um olhar para as mulheres no campo da saúde mental. Temporalis, São Paulo, v. 2, n. 28, 2014. 
PASSOS, R. G.; PORTUGAL, S. Breve balanço da política de saúde mental: uma análise comparativa Brasil e Portugal a partir da experiência das residências terapêuticas. Revista de Políticas Públicas, São Luís, v. 19, n. 1, jan.jun. 2015.

SAFFIOTI, H. I. B. O poder do macho. 11. ed. São Paulo: Moderna, 1987.

SILVA, E. A.; VAZ, B. C.; CAMPOS, F. C. B. Cuidadores e convívio: em cena as relações nos serviços residenciais terapêuticos. In: FURTADO, J. P.; NAKAMURA, E. (Orgs.). Inserção social e habitação de pessoas em sofrimento mental grave. São Paulo: Ed. FAP-Unifesp, 2014.

SORJ, B.; FONTES, A. O care como um regime estratificado: implicações de gênero e classe social. In: HIRATA, H.; GUIMARÃES, N. A. Cuidado e cuidadoras: as várias faces do trabalho do care. São Paulo: Atlas, 2012. 